\title{
WOOLLY HAIR NEVUS TYPE I
}

Anubhav Garg1', Sushma Garg²

\section{HOW TO CITE THIS ARTICLE:}

Anubhav Garg, Sushma Garg. "Woolly Hair Nevus Type I". Journal of Evolution of Medical and Dental Sciences 2014; Vol. 3, Issue 29, July 21; Page: 8048-8050, DOI: 10.14260/jemds/2014/3010

ABSTRACT: Woolly hair nevus is a very rare non hereditary disorder of scalp. It is characterized by presence of one or more circumscribed regions of curly/ kinky, smooth, shiny hair of woolly texture, generally of the lighter color than the normal hair over scalp. In over half of the reported cases, a pigmented or epidermal nevus has been present, but not always at the same site. Its onset is usually within first years of life. We present a case of woolly hair nevus type I with no associated abnormalities, which is quiet rare.

KEYWORDS: Woolly hair, woolly hair nevus, curly hair.

INTRODUCTION: Woolly hair is normal in negroids. However, in non-negroid, it is a hereditary anomaly of the hair. The woolly hair nevus is very rare non-hereditary disorder of the scalp. It is characterized by presence of one or more circumscribed regions of curly/ kinky, smooth, shiny hair of woolly texture, generally of the lighter color than the normal hair over scalp. ${ }^{1}$ The remaining hair on the scalp exhibit no peculiarities. In over half of the reported cases, a pigmented or epidermal nevus has been present, but not always at the same site. ${ }^{2}$ We present a case of woolly hair nevus type I with no associated anomalies, which is quiet a rare phenomenon.

CASE REPORT: We report a case of otherwise healthy 6years old boy, born to non-consanguineous parents who presented to us with a circumscribed patch of curly hair of finer texture than other hair over right parietal scalp (Fig 1) of four years duration. The patch was slowly progressive. There was no history of breakage or fragility of hair, although hair growth in the affected area was somewhat decreased. Birth and developmental history of child was normal, so also the family history was negative for any such condition.

Upon examination, a solitary circumscribed patch of size around $6 \times 6 \mathrm{cms}$ located over right parietal scalp was present. The abnormal hair was curly, short, thinner and lighter than the surrounding scalp hair with normal skin. The hair over rest of the scalp was normal. There was no evidence of inflammation of the scalp, nor was there any nevus elsewhere in the body. Patient was not having any skin or ocular abnormality.

The light microscopic examination of the affected hair showed it to be thinner, more flat, less pigmented and oval on cross-section. Parents were not ready for scalp biopsy. Also it is not necessary as the diagnosis was straight forward by clinical and light microscopic examination. Electron microscopy could not be done due to non-availability of the facility.

The parents were counseled about the benign nature of the condition and were advised no treatment for same.

DISCUSSION: Woolly hair was described first by Gossage in 1907 in a European family. ${ }^{3}$ It is a congenital structural anomaly of scalp hair occurring either sporadically or genetically. Comparing 
this anomaly of the hair shaft with curly hair of black individual, the curled hair of black lies typically separate, while the curls of woolly hair tends to merge. 4

Hutchinson et al had proposed a classification for woolly hair as hereditary woolly hair, familial woolly hair, symmetrical circumscribed allotrichia, woolly hair nevus. ${ }^{5}$ Woolly hair nevus is a rare, non-hereditary condition characterized clinically by one or more, well circumscribed areas of curly/kinky hair on the scalp in a non-black individual. Dr Fred Wise, in 1927, was the first one to describe and coined the term "woolly hair nevus". ${ }^{6}$

Post divided the woolly hair nevus into three categories: a) Type 1: with no associated scalp disorder or hair less skin, b) Type 2: with associated linear verrucous nevus, c) Type 3: acquired, in young adults with short, dark, kinky hair, which has been termed acquired progressive kinking of scalp hair. ${ }^{7}$

Clinically, the woolly hair nevus is characterized by its presence from birth or within first two years of life with one or more well circumscribed areas of the scalp of curly, kinky, shiny hair, of woolly texture, somewhat thinner and lighter in color from the remaining hair. The hair is difficult to comb and often not fragile, except when associated with trichorrhexis nodosa. ${ }^{8}$

The hair in woolly patches usually grows normally. As the anagen phase is truncated, the hair does not grow long and gives false impression of decreased growth. ${ }^{9}$ The nevi generally grow in proportion with the body, reaching to a certain size and remain constant throughout life.

In more than half of the cases reported, woolly hair nevus is associated with verrucous epidermal nevus. Retinal anomalies, retarded bone growth, teeth abnormalities and disturbances in the development of the speech have also been reported. ${ }^{9}$

Most of the cases have onset within first two years of life, although cases described as occurring during adolescence are reported. Both sexes are equally affected. ${ }^{10}$ Histological evaluation is varied in literature and in general, the woolly hair nevus is more of a clinical diagnosis. The microscopic appearance of the affected hair showed it to be thinner, more flat and less pigmented than normal hair.

Electron microscopic findings are characterized by flattened hair with elliptical cross-section, thinner than normal; with reduced transverse diameter. ${ }^{8}$ These findings are helpful in differentiating woolly hair from pili torti, monolethrix or trichorrhexis nodosa and Menkes syndrome. ${ }^{8}$

Woolly hair nevus may be differentiated from other form of woolly hair by being congenital, limited to well demarcated areas of scalp and by abnormal microscopic findings. ${ }^{11}$

Our patient had woolly hair nevus type I i.e. woolly hair nevus without any associated cutaneous or systemic anomalies, which is quiet a rare phenomenon. But this patient had presented to us at a very early age, so he must be followed up regularly to detect any cardiac defect later. As no treatment is currently available, the traumatic physical or chemical cosmetic treatments should be avoided.

\section{REFERENCES:}

1. Grant PW. A case of woolly hair nevus. Arch Dis Child 1960; 35: 512-514.

2. Petirio C, Oliva NP, Zulaica A, Toribio J. woolly hair nevus: report of a case associated with a verrucous epidermal nevus in the same area. Pediatr Dermatol 1989; 6: 188-90.

3. Gossage AM. Inheritance of certain human abnormalities. Quart J Med 1907; 1: 331-347.

4. Mohr OL. Woolly hair, a dominant mutant characteristic in man. J Hered 1932; 23: 345-352. 


\section{CASE REPORT}

5. Hutchinson PE, Cairno RJ, Wells RS. Woolly hair: clinical and general aspects. Trans st Johns Hosp Dermatol Soc 1974; 60: 166-177.

6. Wise F. Woolly hair nevus. A peculiar form of birthmark of the hair the scalp, hitherto undescribed, with report of two cases. Med J Rec 1927; 125: 545-547.

7. Post CHF. Woolly hair nevus. Report of a case. Arch Dermatol 1958: 78; 488-489.

8. Martin-Gonzalez T, Boz-Gonzalez JD, Vera-Casano A. Woolly hair nevus associated with an ipsilateral linear epidermal nevus. Actus Dermosilfiliogr 2007; 98: 198-201.

9. Otberg N, Blume-Peytavi U. Woolly hair syndrome. Orphaned Encyclopedia, Dec 2003: 1-4.

10. De Oliveira JR, Mazocco VT, de Arruda LHF. Woolly hair nevus syndrome. Ann Bras Dermatol 2004; 79: 103-106.

11. Kumaran S, Dogra S, Handa S, Kanwar AJ. Woolly hair nevus. Pediatr Dermatol 2004; 21: 609610.

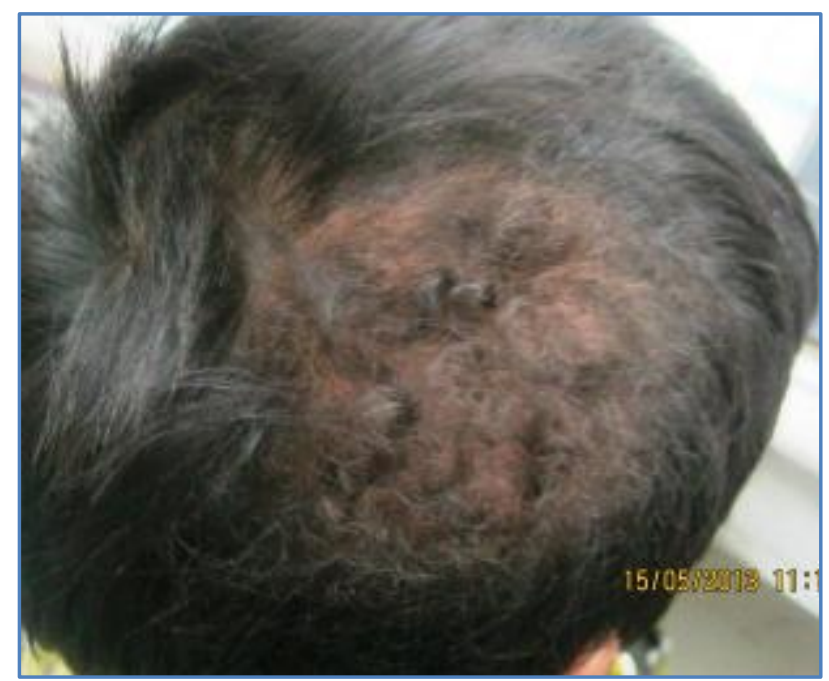

\section{Figure 1: A well circumscribed area of fine,} curly hair over right parietal scalp

\section{AUTHORS:}

1. Anubhav Garg

2. Sushma Garg

\section{PARTICULARS OF CONTRIBUTORS:}

1. Assistant Professor, Department of Skin \& VD, G R Medical College, Gwalior,

2. Consultant Physician, Lashkar, Gwalior.
NAME ADDRESS EMAIL ID OF THE CORRESPONDING AUTHOR:

Dr. Anubhav Garg,

Department of Skin and VD,

G R Medical College,

Gwalior, M. P.

Email: dranubhav1980@gmail.com

Date of Submission: 04/06/2014.

Date of Peer Review: 05/06/2014.

Date of Acceptance: 03/07/2014.

Date of Publishing: 17/07/2014. 